\title{
1 The South African Experience with MSC Certification: A perspective
}

\section{Doug S Butterworth}

Marine Resource Assessment and Management Group (MARAM), Department of Mathematics and Applied Mathematics, University of Cape Town, Rondebosch 7701, South Africa

\begin{abstract}
Perspectives on the South African experience with Marine Stewardship Council (MSC) certification, specifically that of the valuable hake trawl fishery which is as yet the only certified fishery in Africa, are summarised based on discussions with local scientists and fishing industry members. On the positive side, the greatest benefit has been resultant enhanced attention given to science. However the fact that some MSC requirements relate to Government rather than industry responsibilities raises the issue of the extent to which Government omissions should result in penalties to industry. At a broader level, the question of whether it is raising or lowering of MSC standards that is in the best interests of promoting and achieving fisheries sustainability globally is discussed.
\end{abstract}

Keywords: certification, ecolabelling, fishing industry, government, hake, Marine Stewardship Council, tori lines

Corresponding author: D.S. Butterworth

a. Email: doug.butterworth@uct.ac.za

b. Phone: 27-21-650-2343

c. Fax : Not available 


\section{Introduction}

A major objective of ecolabeling is to improve the management and thereby the status of the world's fisheries by creating market-related incentives. Many of the world's overexploited fisheries are in the developing world, so with South Africa (SA) straddling the developeddeveloping divide, it is of particular interest to examine how Marine Stewardship Council (MSC) certification has fared in the country.

The South African trawl fishery for hake, for which landed values exceed those for the rest of the country's fisheries combined, is currently the only MSC certified fishery in Africa. This paper reports on local perspectives regarding this certification, as ascertained from discussions with local scientists and members of the fishing industry, though the majority of the views reported have originated from Roy Bross (Secretary of the SA Deep Sea Trawling Industry Association - the body that sought the certification - who sadly passed away recently), Kim Prochazka (Director of Research of the Fisheries Branch of the SA Department of Agriculture, Forestry and Fisheries, which carries management responsibility for this fishery), and the author who has been heavily involved in the quantitative scientific assessments of this hake resource.

The paper first summarises the history of the MSC certification of the hake trawl fishery, and then proceeds to discuss perceived positive and negative associated aspects.

\section{The hake fishery and its certification history}

The hake caught off South Africa actually comprises two species, the shallow-water hake Merluccius capensis and deep-water hake M. paradoxus. Over recent decades, the annual Total Allowance Catch (TAC) has generally not differed greatly from 150 thousand tonnes.

Lallemand et al. (this volume) describe social and economic aspects of the fishery. In brief, the fishery provides direct employment for over 8000 persons, which nears $40 \%$ of the total direct employment in the SA fishing industry as a whole. Approaching $70 \%$ of the product is exported, resulting in an annual revenue approaching USD 200 million. Importantly, Lallemand et al. emphasise the current economic importance to the industry of access to northern European markets to sell high-price products. This access is dependent on MSC certification, without which many buyers would decline to purchase these hake. Should MSC certification not continue, Lallemand et al. estimate a loss of some $40 \%$ of the five-year Net Present Value of the fishery, and report estimates by others of direct and indirect employment losses ranging between 5000 and 10000. Clearly continuation of MSC certification is of great importance to the hake trawl industry at this time.

The first MSC certification of the hake trawl fishery was achieved in 2004. The associated evaluation was fairly straightforward, particularly as at the time the two hake species were assessed as one. With the two species aggregated, although hake was estimated to be below its MSY biomass level ( $\mathrm{B}_{\mathrm{MSY}}$ ), it was acknowledged to be well advanced along an acceptable recovery trajectory.

However re-certification in 2010 saw this picture change substantially. In 2006 the hake assessment had been successfully disaggregated by species for the first time, with results that showed the shallow-water species above but the deep-water species well below the biomass

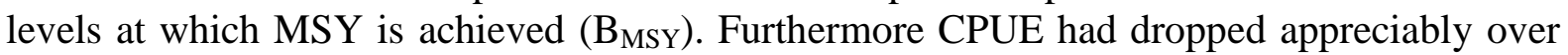
the immediately preceding years, greatly reducing the industry's profit margins, and furthermore concerns had developed given estimates of the number of seabirds killed during fishing operations.

This re-certification exercise nevertheless concluded with a successful outcome. The main reasons were the implementation of a recovery plan (in the form of a Management Procedure (MP) (Butterworth, 2007; Rademeyer et al., 2008)) which was projected to return the deep-water hake biomass to its MSY level by 2016 (Rademeyer, 2012), widespread 
introduction of tori lines which achieved a seabird kill reduction estimated to have exceeded $90 \%$, and the initiation of an experiment to investigate the impact of trawling for hake on the habitat.

The 2015 re-certification proved more challenging still. With the northward shift in the European market for South African hake following the 2008 financial crisis, with concomitant increasing insistence on MSC certification, for the first time the industry saw clearly how exposed it was, with thousands of jobs at risk if re-certification was refused. Although ultimately this re-certification was again achieved, this accomplishment was rendered more difficult given some negative resource signals as well as some Government administrative problems.

Following some good recruitment, the deep-water hake had reached $\mathrm{B}_{\mathrm{MSY}}$ in 2013 rather than 2016 as projected at the time of the previous re-certification, but subsequent poor recruitment had been detected, and even given anticipated TAC reductions in terms of an updated MP, a short term reduction in biomass was projected for the next few years with a return to $\mathrm{B}_{\mathrm{MSY}}$ only after 2020. Furthermore there were problems in maintaining the certification requirement of an observer programme in the fishery, and in the lack of availability for a number of years of the country's main research vessel to conduct the key trawl surveys that provided the estimates hake abundance required for TAC computations (with an industry fishing vessel having to substitute, though without any inter-vessel calibration exercise proving possible). However both of these last two problems were matters for Government to rectify, and outside the control of the industry seeking re-certification.

\section{The positives}

MSC certification has brought further (though limited) market penetration, and has incentivised tori line use which has led to appreciable reductions in bird kills.

However, perhaps the greatest benefit has been the enhanced attention now given to scientific considerations and inputs.

- The results from scientific analyses (assessments and the MP development process) are now taken more seriously by both industry stakeholders and Government officials.

- The implications of loss of MSC certification provides a potential "stick" to "encourage" both Government and industry to take steps to improve (or at least maintain) good management of the fishery.

- Exposure to the process has "conscientised" (a Roy Bross-ism) the industry to sustainability considerations.

- Programmes to educate skippers and crew on these sustainability considerations have been initiated.

- A common industry ethos regarding these considerations has emerged. It is however likely that this proved possible only because of a limited number of players (although rights holders in the hake trawling industry include a large number with small quotas, these all work through only nine vessel operators).

\section{The negatives}

\subsection{Standards}

Initially MSC requirements were generally fairly broad in nature: "move the stock in the right direction". Subsequently they have become more prescriptive (see MSC, 2014). There are differing local views on this. The one is that they are now "too prescriptive" (too "North Atlantic-like"). The other is that they are not prescriptive enough, for reasons evident from the practical example below that arose in the recent revision process for the MP which is used to provide TAC recommendations for the SA hake resource. 
Figure 1 shows the projections that came under discussion in the domestic process of the 2014 revision of the MP for the hake resource. Although the deep-water hake population was estimated to have recovered to $\mathrm{B}_{\mathrm{MSY}}$ by 2013 , indications of recent poor recruitments led to the range of MPs under considerations projecting that even with moderate TAC reductions in the short term, this population would drop by about 30\% in abundance by 2017 before recovering to the neighbourhood of $\mathrm{B}_{\mathrm{MSY}}$ by about 2021 (Rademeyer and Butterworth, 2014). Comparing the candidate Management Procedure options $\mathrm{CMP}_{140}$ and $\mathrm{CMP}_{135}$ shown in Figure 1 indicates that the former implicitly targets an eventual median abundance of about $95 \%$ of $\mathrm{B}_{\mathrm{MSY}}$ and the latter about $105 \%$ of $\mathrm{B}_{\mathrm{MSY}}$. Although the latter has the advantage of a CPUE that is about $4 \%$ higher, the former provides an extra catch averaging 5000 tons extra annually (worth about USD 11 million), and would provide employment for about 300 extra people (based on statistics in Lallemand et al., this volume) in a country where job creation is perhaps the highest national priority.

In domestic discussions, a key issue that arose was that although overall these trade-offs seemed to suggest that the $\mathrm{CMP}_{140}$ option was to be preferred, it was unclear whether the certification team reviewing the certification re-application would accept a target of $95 \%$ of $\mathrm{B}_{\mathrm{MSY}}$ (a quantity for which the value estimated was in any case uncertain) as being consistent with MSC criteria (MSC, 2014) which understandably are not entirely prescriptive on this point. Hence this would be a matter for the certification team to use their discretion. Accordingly the domestic scientific working group responsible for recommending a choice (this group included participating observers from the hake industry and environmental nongovernmental organizations) desired direct interaction with the certification team to ascertain which MP options they considered to be consistent with the MSC criteria. Exactly the same issue had arisen on the previous occasion the hake MP was revised (in 2010) - see Figure 2.

The fundamental difficulty was that the local scientific working group wanted to avoid the operational disadvantages of making a choice, only to be told some time later by the certification team that it did not consider that choice in line with MSC criteria, and hence would recommend withdrawal of certification unless the choice was amended to be more conservative. This could have been achieved had the scientific working group been able to engage with the certification team at the time the choice was under domestic discussion. BUT current MSC regulations forbid such engagement. These regulations need urgent revision to allow such interaction so as to circumvent this obstacle to efficient management.

\subsection{Governance}

The certification-related problems that arose because of suspension of an observer programme and of the availability of the country's main research vessel to provide survey estimates hake abundance required for TAC computations have been mentioned above. The associated difficulty for the industry group applying for re-certification was that these matters were the responsibility of Government, and outside the control of industry.

This raises the issue of whether the MSC certification process needs to involve formalised arrangements with Governments as well as with the industry groups that are seeking certification, given that some MSC requirements relate to Government rather than industry responsibilities. However to be reasonable and practical, those requirements would need in turn to factor in the bureaucratic processes and funding limitations within which Governments have to operate, and to accept that this means that current standards cannot always be improved - indeed some may have to drop during certain periods when funds are more limited.

The MSC needs to consider how crucial its certification requirements are in some of these areas - should not the primary certification consideration be whether or not sustainable utilisation is being seriously compromised? Further, does more flexibility need to be 
considered, e.g. accepting observer programmes which are organised and paid by the fishing industry, provided there is evidence of structures that maintain the necessary independence of observers and preclude possible undue pressure from industry being exerted?

\subsection{Losing the plot?}

A key question raised by stakeholders in discussions was whether the MSC had lost the plot, and together with that whether it was effectively "preaching only to the converted"? A corollary is that there is an incentive for the "converted", not to evangelise, but rather to seek to keep others excluded from the certification "club" so as to limit the availability of the economic benefits of certification to themselves. Certainly some developing countries view the MSC as primarily a mechanism for developed countries to erect what amount to trade barriers against imports from their fisheries.

Reports of continued pressure on the MSC to raise its standards further are a concern. There are two negative aspects associated with this. First there is the matter of fair play and the associated credibility of the MSC as an "honest broker". The reality is that in public relations terms, for a fishery first to be certified but later no longer be certified is worse than never having been certified in the first place. Public perception will always link such an eventuality with failure by the industry to maintain conduct consistent with sustainability, rather than the (questionably defensible) practice of "raising of the bar". Thus the possibility of such occurrences creates a disincentive for fisheries to seek certification. Secondly such raising of the bar loses leverage to persuade fisheries performing poorly to seek certification, and consequently need to improve that performance. If such fisheries come to see no chance of achieving certification, any incentive for them to improve will be lost.

Bluntly put, the MSC would seem to be approaching a crossroads. Is the primary objective of its certification process:

a) achieving marginal improvements in the performance of the $10 \%$ of the world's fisheries that are the best managed; or

b) promoting and achieving sustainable use in the majority of the other $80-90 \%$ ?

If $b$ ) is indeed the more important, that then raises the question of whether the MSC should be lowering its standards, or alternatively developing a two-tier system with the lower of two standards reflecting a realistic medium term goal for the majority of fisheries, and in particular those in the developing world, to best achieve that goal.

\subsection{In summary}

In South Africa, MSC certification of the hake fishery has enhanced the role of science in local fisheries management together with the focus on sustainability. However it has also raised the issue of the extent to which a fishing industry should possibly be penalised for the omissions of Government.

From a broader perspective, the question arises of whether possible bar-raising of MSC standards is in the interests of promoting and achieving fisheries sustainability globally. Indeed, to the contrary, the MSC would seem to need to address the question of whether some lowering of its standards might better achieve that goal.

\section{Acknowledgements}

I thank a number of local fishery scientists and fishing industry stakeholders for the discussions on which this document is based, particularly Kim Prochazka of the Fisheries Branch of the SA Department of Agriculture, Forestry and Fisheries and the late Roy Bross of the South African Deep Sea Trawling Industries Association, as well as Rebecca Rademeyer for assistance with the Figures. 


\section{References}

Butterworth, D.S., 2007. Why a management procedure approach? Some positives and negatives. ICES J. Mar. Sci. 64, 613-617.

Lallemand, P., Bergh, M., Hansen, M., Purves, M. This volume. Estimating the economic benefits of MSC certification for the South African hake trawl fishery. Fish. Res. 00, 0000 .

MSC. 2014. MSC Fisheries Standard and Guidance v2.0. 290 pp. Available at https://www.msc.org/documents/scheme-documents/fisheries-certification-schemedocuments/fisheries-standard-version-2.0

Rademeyer, R.A., Butterworth, D.S., Plagányi, É.E., 2008. A history of recent bases for management and the development of a species-combined Operational Management Procedure for the South African hake. Afr. J. Mar. Sci.30, 291-310.

Rademeyer, R.A., 2012. The evolution of management procedures for the South African hake resource in the 2000s. PhD Thesis. 381 pp. University of Cape Town, South Africa. Available at http://www.math.uct.ac.za/maram/pub/theses/PhD_Rebecca_Rademeyer.pdf.

Rademeyer, R.A., Butterworth, D.S., 2014. Candidate management procedures projections for the South African hake resource. Unpublished South African Department of Agriculture, Forestry and Fisheries document, FISHERIES/2014/AUG/SWG-DEM/33. 15

pp.

Available

at http://www.mth.uct.ac.za/maram/pub/2014/FISHERIES_2014_AUG_SWG-DEM_33.pdf 

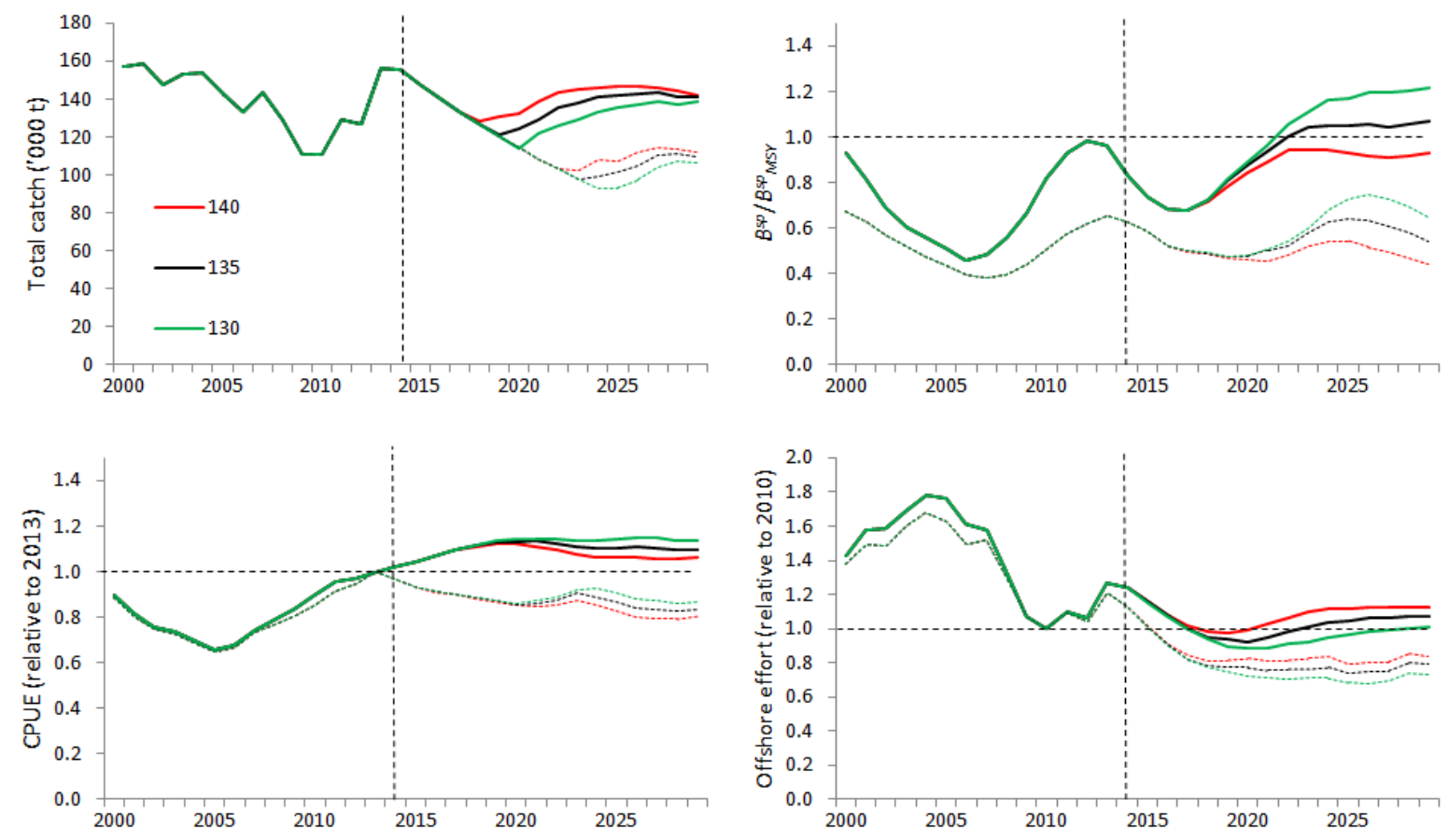

Figure 1. Medians (full lines) and lower 2.5\%iles (dotted lines) for the annual total hake allowable catch (TAC - top row, LHS), M. paradoxus spawning biomass (relative to $\mathrm{B}_{\mathrm{MSY}}$ top row, RHS), CPUE (relative to 2013, bottom row, LHS) and effort (relative to 2010, bottom row, RHS) for the reference set of operating models used for testing Candidate MPs for the 2014 hake MP revision process (Rademeyer and Butterworth, 2014). Results are shown for three Candidate MPs: CMP1 $\mathbf{1 4 0}_{14}, \mathbf{C M P 1}_{135}$ and $\mathbf{C M P 1}_{\mathbf{1 3 0}}$ (corresponding to anticipated average TACs over 2015-2024 of 140,000t, 135,000t and 130,000t respectively). The horizontal dashed lines correspond to $M$. paradoxus at $\mathrm{B}_{\mathrm{MSY}}$. Projections start to the right of the vertical dashed lines. 

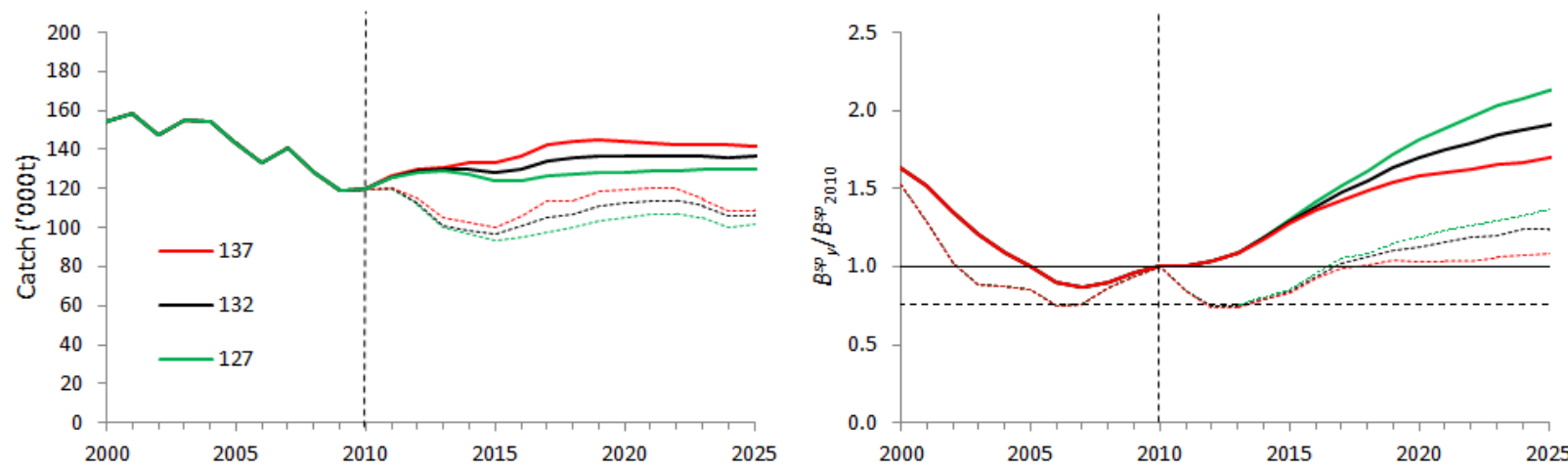

Figure 2. A similar plot to that shown in Figure 1, but here for the 2010 hake MP revision process (taken from Rademeyer, 2012). In the top RHS plot $M$. paradoxus spawning biomass projections (to the right of the vertical dashed line) are shown relative to their 2010 level. Results are shown for three candidate MPs: CMP1 $1_{137}, \mathbf{C M P 1 _ { 1 3 2 }}$ and $\mathbf{C M P 1 _ { 1 2 7 }}$ (corresponding to anticipated average TACs over 2011-2020 of 137,000t, 132,000t and $127,000 t$ respectively). 